\title{
Influence of the Shape of the Filling on the Mechanical Properties of Samples Made by 3D Printing
}

\author{
Zdeněk Joska ${ }^{1}$, Lukáš Andrés ${ }^{1}$, Tomáš Dražan ${ }^{1}$, Karel Maňas ${ }^{2}$, Zdeněk Pokorný1 ${ }^{1}$ Josef Sedlák ${ }^{3}$ \\ ${ }^{1}$ Department of Mechanical Engineering, Faculty of Military Technology, University of Defence, 66210 Brno, \\ Czech Republic. E-mail: zdenek.joska@unob.cz \\ ${ }^{2}$ Department of Aircraft Technology, Faculty of Military Technology, University of Defence in Brno, 612 10, CZ \\ Czech Republic. E-mail: karel.manas@unob.cz \\ 3Department of Industrial Engineering and Information Systems, Faculty of Management and Economics, Tomas \\ Bata University in Zlín, Mostní 5139, 76001 Zlín, Czech Republic. E-mail: sedlak@utb.cz
}

In this work, the influence of material type and sample fill density was evaluated. One PLA material was tested. Test specimens having different fill structure and density were printed from this material. Full honeycomb and gyroid shapes were used for the fill structure. The specimens had four different fill percentages for each structure: $10 \%, 25 \%, 50 \%$ and $75 \%$. These bodies were compared to samples that were printed with $100 \%$ fill. Tensile test was performed on printed test pieces. The Zwick / Roell Z100 was used for testing and the surface hardness of the test specimens was measured by the Shore $D$ method on a DIGI-Test II hardness tester. Fracture surfaces were evaluated on an Olympus DSX 500 optodigital microscope. The results showed that the shape of the fill did not signifi-cantly affect the values obtained by the tensile test. The hardness measurement results showed a different hardness on the bottom surface that was in contact with the printing pad and the top printing surface. Fractographic analysis revealed different types of fracture surfaces related to the printed fill structure.

Keywords: 3D printing, tensile test, hardness, infill

\section{Introduction}

A simple definition for $3 \mathrm{D}$ printing is that it is the process by which a three-dimensional object is created from a di-gital file. With the help of additive manufacturing (AM) a process is achieved how to give a digital file a material shape by means of additive processes [1]. However, a virtual design in the form of a CAD file must be performed before prin-ting can begin. This can be achieved either through the conventional design process in programs such as AUTOCAD or CATIA, or through more modern technology such as 3D scanning or recognition [2]. Not all 3D printers use the same type of technology, and it may be appropriate to use more than one type for a given project. Since 2010, the American Society for Testing and Materials (ASTM) "ASTM F42 - Additive Manufacturing" has developed a set of standards that categorize additive manufacturing processes into 7 basic types [3]. The FDM / FFF method is one of the most used and widespread technologies used in $3 \mathrm{D}$ printing. The principle of this technology is to melt thermoplastic or metal. The most used materials (thermoplastics) include, for example, ABS or PLA. The length of the print itself depends on the size and complexity of the prints, it can reach up to tens of hours. The FDM /
FFF method can achieve very good mechanical properties for the products, thanks to which these products can be used, for example, as mechanical components. An indisputable advantage is also the simplicity and the generation of minimal waste, which consists only of the already mentioned supporting material [4]. Disadvantages can be considered, for example, the limited accuracy, influenced by the material itself and the nozzle from which the material is extruded. It is also necessary to take into account the shrin-kage of the final product, which occurs when the material solidifies. However, this phenomenon can be compensated by corrections in the system preparing the print data $[5,6]$. It is the second most used and most universal material for FDM / FFF technology and 3D printing in general. PLA is a thermoplastic polyester that is obtained from renewable sources such as potato or corn starch. Unlike ABS, this material is less prone to deformation and has good strength, even at lower temperatures. Disadvantages can be considered, for example, less resistance to higher temperatures (softening begins at $60^{\circ} \mathrm{C}$ ), which is related to machine grinding, which is not recommended for this material, because the material is quickly heated in this process to the point where it begins to soften ( this problem can be prevented by cooling). PLA is also less flexible than ABS $[7,9,10]$. 


\section{Experimental procedure}

Tensile test is one of the basic tests used to determine the mechanical characteristics to determine the quality of the material. The samples was printed according to the standard ČSN EN ISO 527-2[8]. The hardness of material was tested Shore D method on DIGITest II hardnes tester device. The samples used for testing have thickness of $4 \mathrm{~mm}$.

\section{Sample preparation}

For the experimental part, 45 samples were printed according to the ISO 527-2 standard. 20 with Full honeycomb fill pattern, 20 with Gyroid fill pattern with fill percentages of $10 \%, 25 \%, 50 \%, 75 \%$ and 5 samples with $100 \%$ fill for com-parison see Fig 1. and 2.

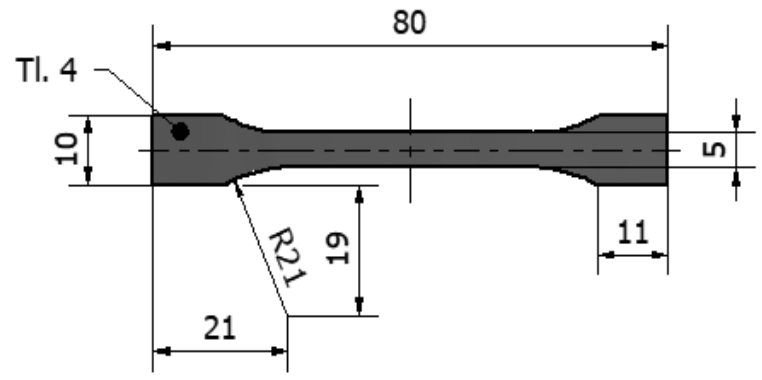

Fig. 1 Sample ISO 527-2 (Type A)

Five test specimens for each type and percentage of infill. Where the sample shell was $0.8 \mathrm{~mm}$ and only the infill was changed. PLA samples were printed with a $0.4 \mathrm{~mm}$ diameter nozzle at $215^{\circ} \mathrm{C}$ on a $35^{\circ} \mathrm{C}$ heated substrate pad with a layer height of $0.2 \mathrm{~mm}$. The first two and last two layers were printed with a Rectilinear pattern at an angle of $45^{\circ}$.

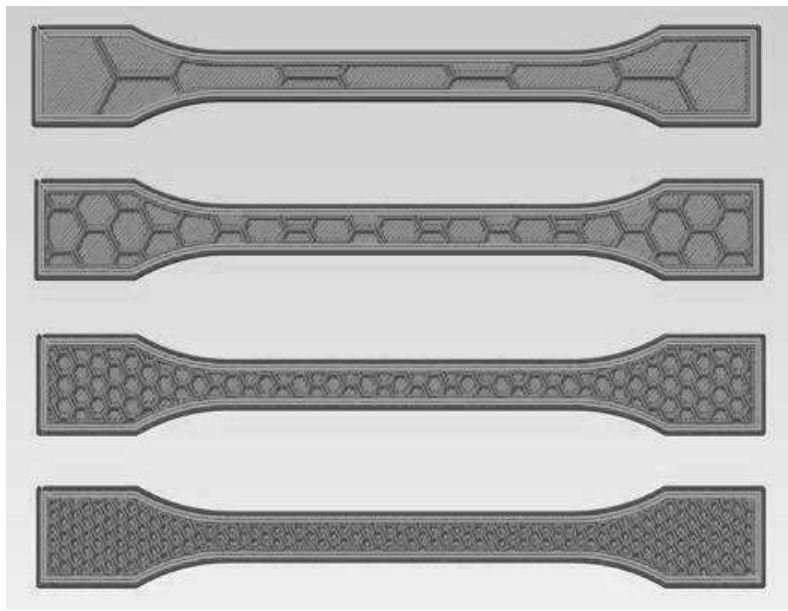

Fig. 2 Samples Full honeycomb

Second serie of samples see Fig 3. and Fig 4. For experiment 45 samples were printed. 20 with Full honeycomb fill pat-tern, 20 with Gyroid fill pattern and
5 with 100\% fill for comparison. 5 test specimens for each species and percentage of infill. Where, instead of the shell, only one perimeter was printed around a $0.4 \mathrm{~mm}$ wide test specimen. PLA samples were printed with a $0.4 \mathrm{~mm}$ diameter nozzle at $215^{\circ} \mathrm{C}$ on a $35^{\circ} \mathrm{C}$ heated substrate with a layer height of $0.2 \mathrm{~mm}$.

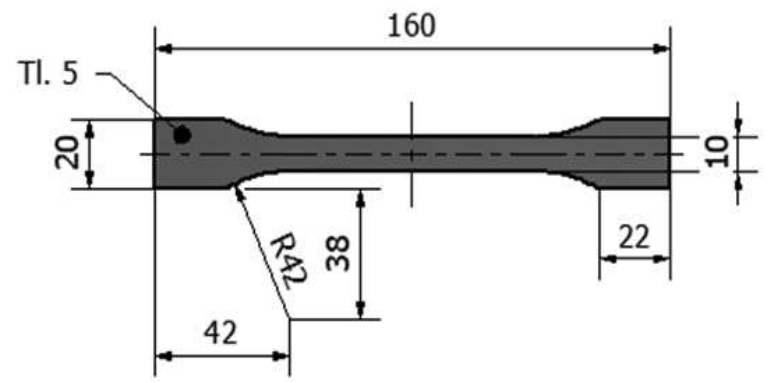

Fig. 3 Own design of the modified sample (Type B)

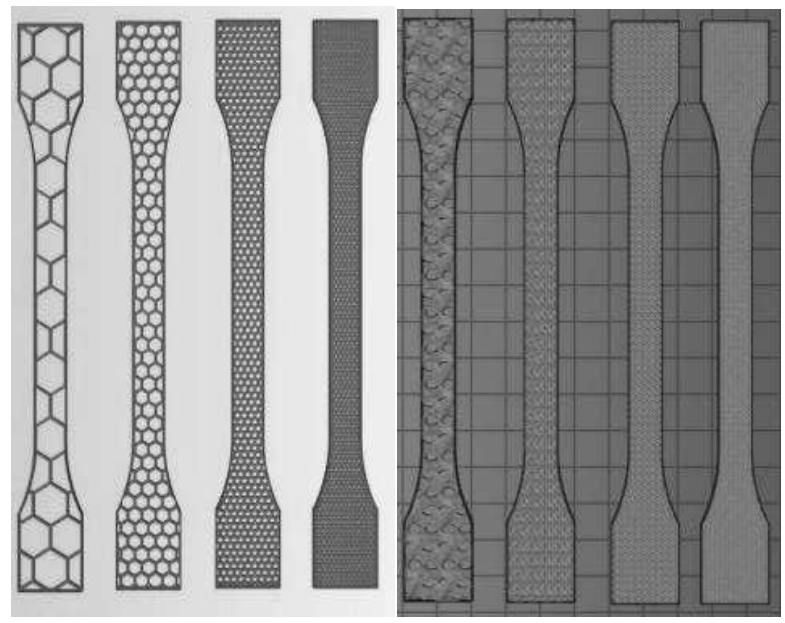

Fig. 4 Full honeycomb (left), Gyroid (right)

\section{Results}

\section{Weight and time of printing of test samples}

The weight and time of printing and the associated price of printing are probably the main reasons why to choose a different fill of prints and not leave the printout full. Only the modified sample (Type B) will be compared because it does not distort the shell result. The results show that Gyroid offers a greater saving of printing time compared to Full honeycomb by about $20 \%$ see in Tab. 1 . Because printing was performed in batches, the table does not show the exact print time but the total print time of the batch divided by the number of pieces. Over time, the print head passes between prints are also taken into account, but this does not affect the percentage of time saved. At higher infill densities, Full honeycomb is better in weight, but at lower infill densities Gyroid. Only depending on the printing time and weight of the printout, the Gyroid comes out better. 
Tab. 1 Print weight and time (Type B)

\begin{tabular}{|l|c|c|c|c|}
\hline \multicolumn{1}{|c|}{ Type of infill } & Printing time [min] & Weight [g] & Time saved [\%] & Weight saved [\%] \\
\hline Full infill & 79 & 13.55 & 0 & 0 \\
\hline Full honeycomb 75\% & 64 & 9.27 & 18.99 & 31.59 \\
\hline Gyroid 75\% & 40 & 10.17 & 49.37 & 24.94 \\
\hline Full honeycomb 50\% & 46 & 6.94 & 41.77 & 48.78 \\
\hline Gyroid 50\% & 24 & 7.25 & 69.62 & 67.49 \\
\hline Full honeycomb 25\% & 30 & 4.39 & 62.03 & 69.15 \\
\hline Gyroid 25\% & 13 & 4.18 & 83.54 & 81.40 \\
\hline Full honeycomb 10\% & 19 & 2.52 & 75.95 & 83.10 \\
\hline Gyroid 10\% & 7 & 2.29 & 91.14 & 60 \\
\hline
\end{tabular}

Tensile test of standard sample (Type A)

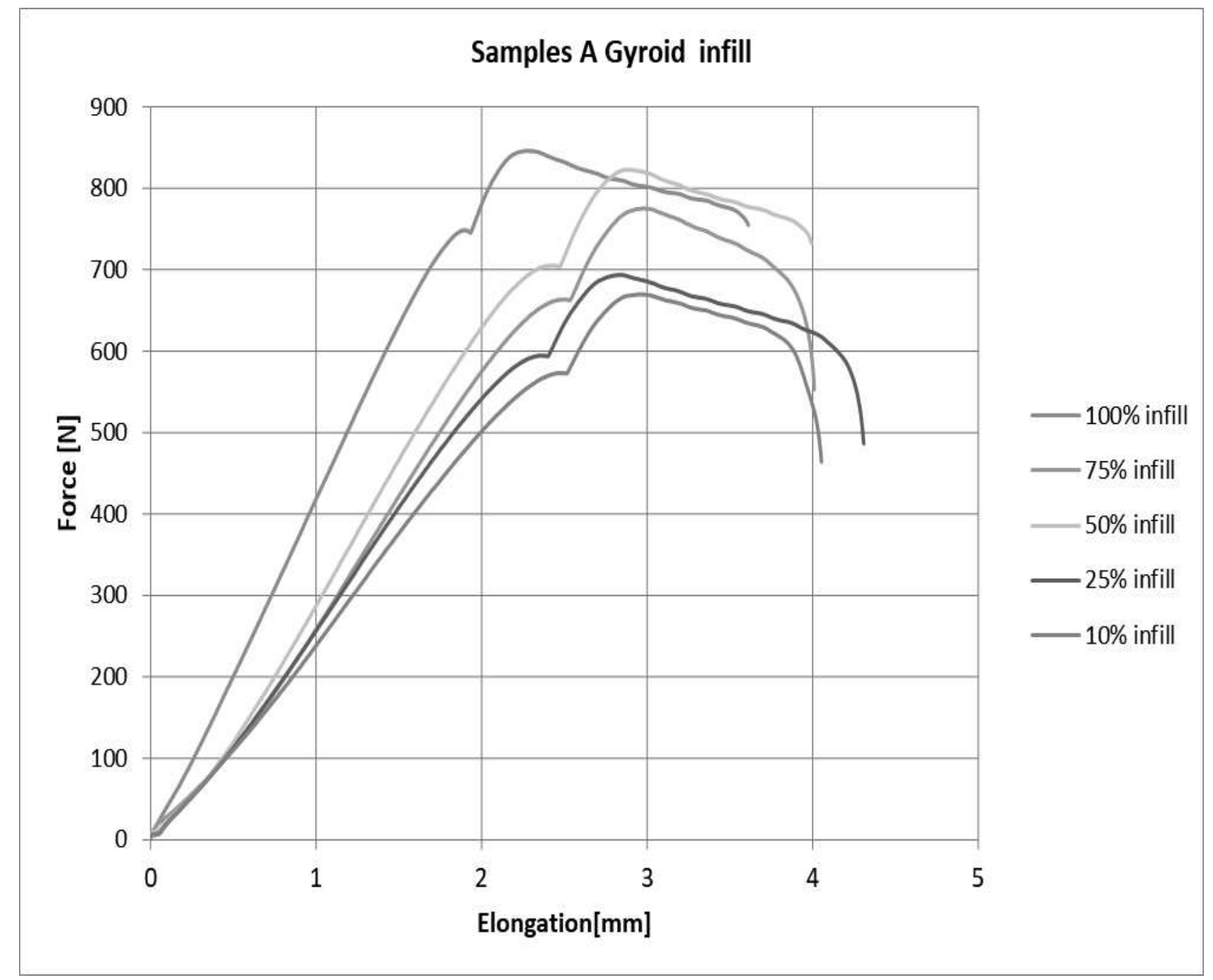

Fig. 5 S ample with gyroid infill (Type A) 


\section{Samples A Fullhoneycomb infill}

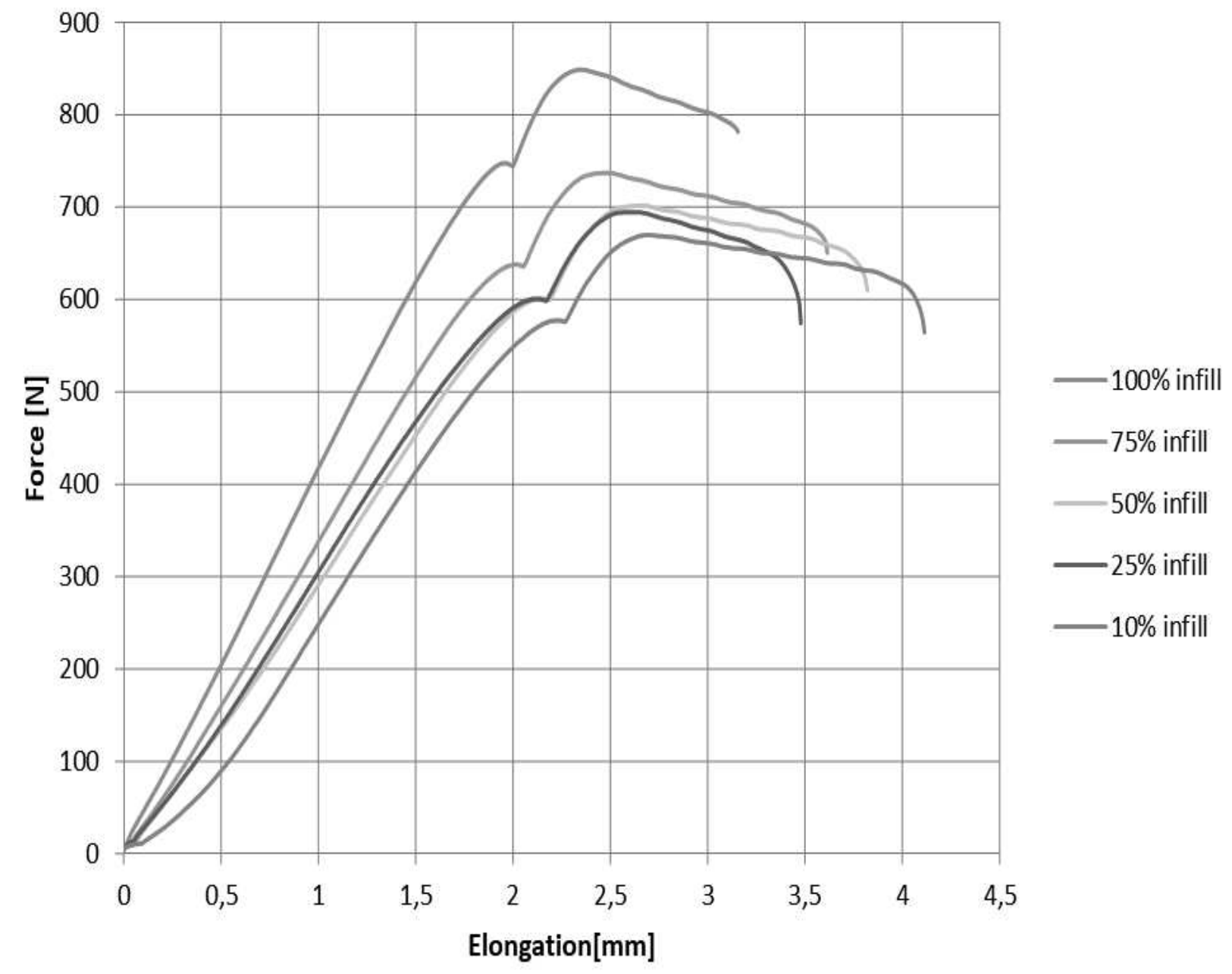

Fig. 6 Sample with Full honeycomb infill (Type A)

Tab. 2 Maximal force (Type A)

\begin{tabular}{|c|c|}
\hline Type infill & Max. force F [N] \\
\hline Full infill & 849 \\
\hline Full honeycomb 75\% (Type A) & 737 \\
\hline Gyroid 75\% (Type A) & 822 \\
\hline Full honeycomb 50\% (Type A) & 701 \\
\hline Gyroid 50\% (Type A) & 775 \\
\hline Full honeycomb 25\% (Type A) & 694 \\
\hline Gyroid 25\% (Type A) & 669 \\
\hline Full honeycomb 10\% (Type A) & 670 \\
\hline Gyroid 10\% (Type A) & 669 \\
\hline
\end{tabular}


Tensile test of modified sample (Type B)

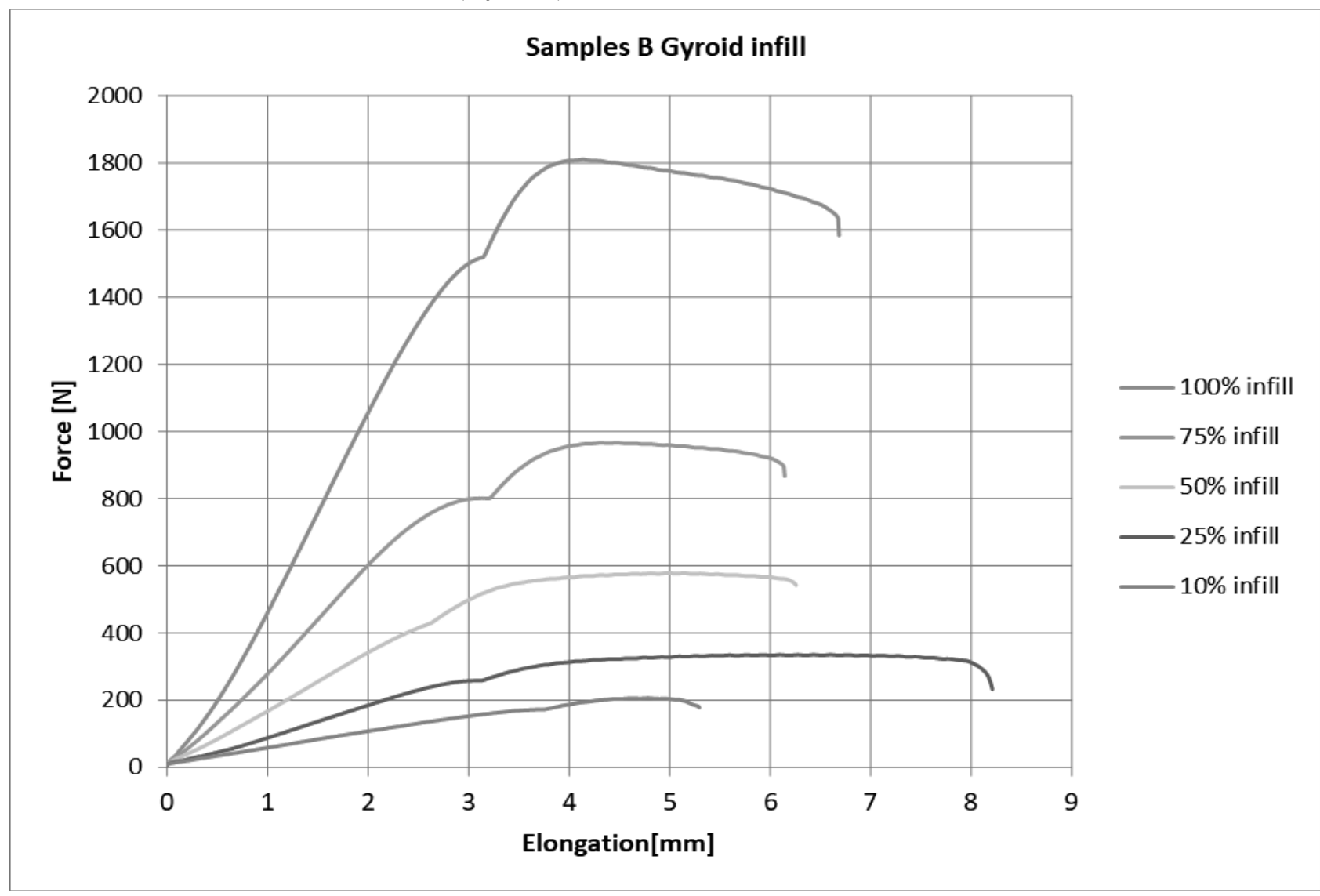

Fig. 7 Sample with gyroid infill (Type B)

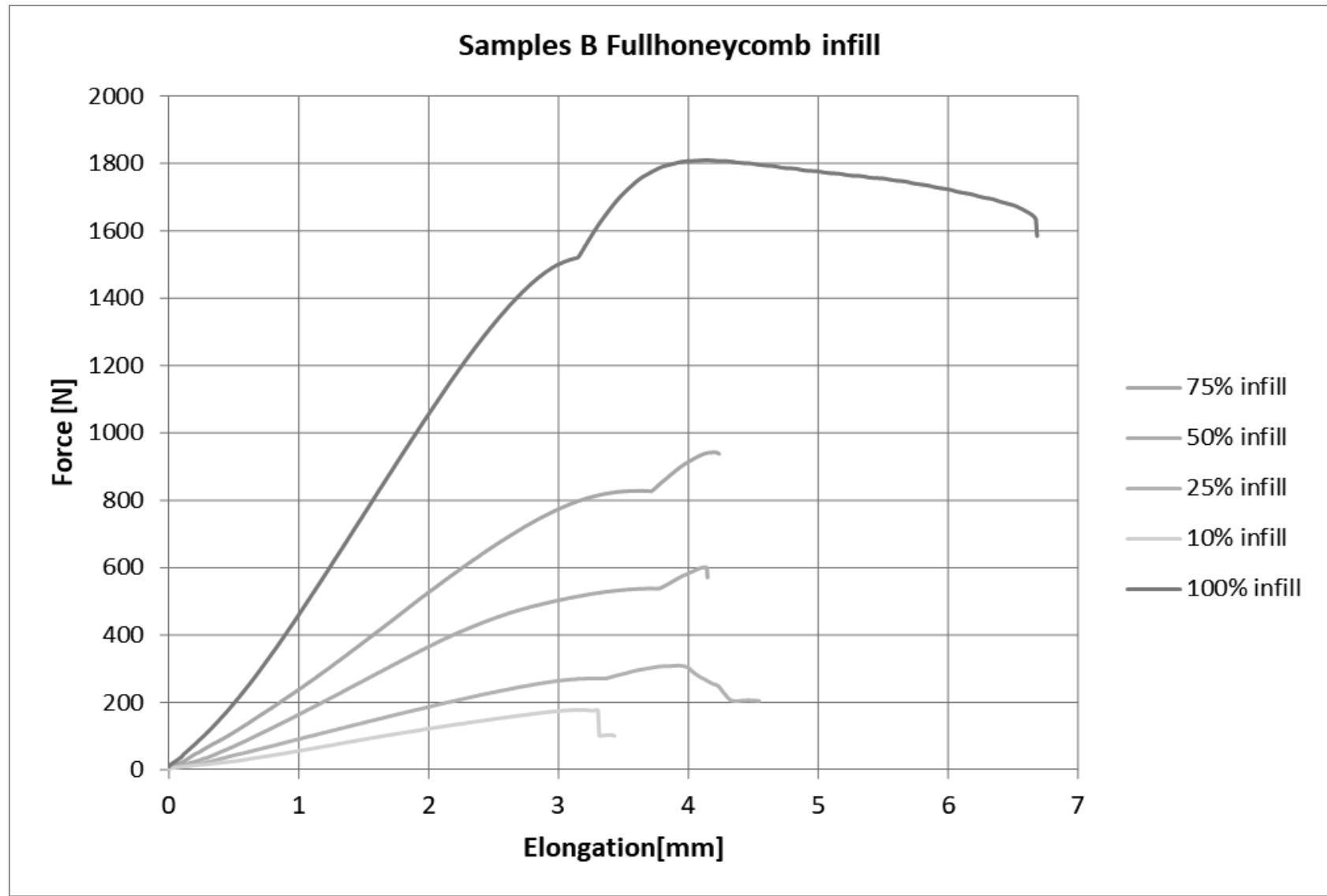

Fig. 8 Sample with Full honeycomb infill (Type B) 
Tab. 3 Maximal force (Type B)

\begin{tabular}{|c|c|}
\hline Type of infill & Max. force F [N] \\
\hline Full infill & 1809 \\
\hline Full honeycomb 75\% (Type B) & 942 \\
\hline Gyroid 75\% (Type B) & 966 \\
\hline Full honeycomb 50\% (Type B) & 600 \\
\hline Gyroid 50\% (Type B) & 578 \\
\hline Full honeycomb 25\% (Type B) & 309 \\
\hline Gyroid 25\% (Type B) & 334 \\
\hline Full honeycomb 10\% (Type B) & 177 \\
\hline Gyroid 10\% (Type B) & 205 \\
\hline
\end{tabular}

Figures 5-8 show the results of tensile tests of individual shapes of test bars with different shape and infill content. The results show that for type A samples the differences during the tensile test are less different than for type B samples. The achieved maximum forces given in Tables 2 and 3 show that the shape of the maximum force is again not affected by the infill shape. The results showed that the content of the infile and the shape of the printing of the edge surfaces have a great influence on the course and results, which significantly influence the test values. For low infile Tab. 4 Surface hardness

\begin{tabular}{|c|c|c|}
\hline Sample number & Side in contact with the pad & Upper side \\
\hline 1 & 77.6 & 67.7 \\
\hline 2 & 77.1 & 68.8 \\
\hline 3 & 77.0 & 66.0 \\
\hline 4 & 77.0 & 69.8 \\
\hline 5 & 76.6 & 66.9 \\
\hline Average value & $\mathbf{7 7 . 0 \pm 0 . 3 2}$ & $\mathbf{6 8 \pm 1 . 3 5}$ \\
\hline
\end{tabular}

The Table 4. shows that the surface hardness of the surface in contact with the pad is $13.6 \%$ higher than on the side that was not in contact with the printing pad.

\section{Fracture analysis}

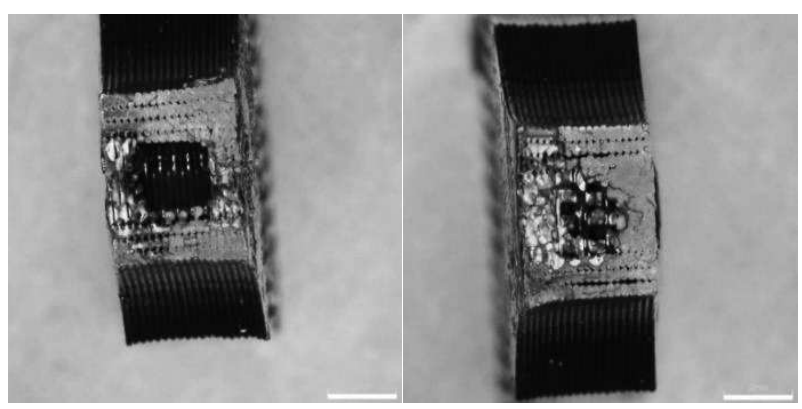

Fig. 9 Full honeycomb $25 \%$ ( left), Gyroid $75 \%$ (right)

The effect of the shell on the fracture surface can be easily observed on this type of sample Fig $9 \ldots$ The fracture does not tend to change due to the type of filling or the percentage of filling. As an example, Full contents of $10 \%$ and $25 \%$, the differences are not as significant as for higher infile contents.

\section{Hardness}

To compare the surface hardness of the printed sides of samples was used method Shore D plastics. For experiment was used DIGI-Test II. The measurements were performed on five samples with full filling and were performed on both surfaces ten times. We only insert the average value from the measurement into the table. honeycomb 25\% and Gyro-id 75\% and the fractures are almost identical.

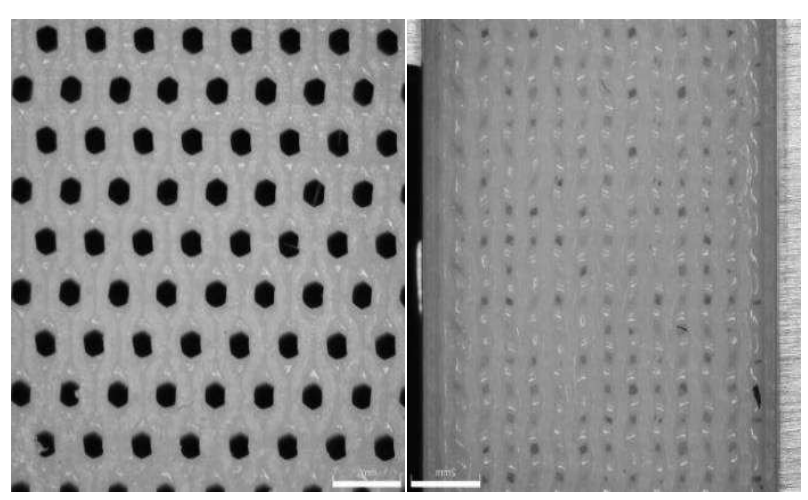

Fig. 10 Full honeycomb 75\% surface (left), Gyroid 75\% surface (right)

For this type of sample, we can better observe the effect of the filling structure on the fracture of the sample. With Gyroid see Fig 10., the fracture is transverse due to the application of layers. With Full honeycomb, the fracture is slanted due to the positions of the holes in the filling. 


\section{Conclusion}

The measurement results showed that the printing of the Gyroid infill type is on average $23.73 \%$ faster than the Full honeycomb infill. Furthermore, the average weight of a print with the Full honeycomb pattern is $1.42 \%$ lower than that of the Gyroid. For the tensile test, measurements were performed on two types of samples with and without shell. For the smaller shell samples (Type A), the results were quite similar for all the different infill percentages. It can be observed that the shell has big influence on results of tensile test. For modified larger samples without shell with only one perimeter around the circumference (Type B), the results were more pronounced for the individual percentages of the infill. For the tensile test, only data of maximal tensile strenght was compared. For the Type A sample, the Gyroid type performed better in average strength by $6.81 \%$, tensile strength by $12.59 \%$ than with the Full honeycomb type. For the Type B sample, the Gyroid type performed better with an average strength of $1.16 \%$, tensile strength of $1.86 \%$. The surface strength on the surface that was in contact with the printing pad is $13.6 \%$ higher than on the surface that was not in contact with the printing pad. Comparison of the fracture surfaces of the samples showed the influence of the type of infill on the fracture of the part.

For Type B, where the result was not distorted by the shell, the Gyroid filling type turned out a little better than the Full honeycomb type, but with regard to the printing time, the Gyroid works better overall than the Full honeycomb.

\section{Acknowledgement}

The work presented in this paper has been supported by the specific research project 2020 „SV20-216"at the Department of Mechanical Engineering, University of Defence in Brno and the Project for the Development of the Organization „DZRO Military autonomous and robotic systems".

\section{References}

[1] CHUA, C. K., LEONG, K. F., LIM, C. S. (2010) Rapid Prototyping: Principles and Applications. 3rd ed. New Jer-sey: World Scientific, 512 pp. ISBN 978-981-277-897-0.

[2] DRÁPELA, M. (2006) Modul Rapid Prototyping. Centrum vzdělávání a poradenství Vysokého učení technického v Brně, $44 \mathrm{~s}$.

[3] The History of 3D Printing: 3D Printing Technologies from the 80s to Today. Scuplteo [online]. 14. pros-ince 2016 [cit. 2019-04-11]. Dostupné bttps:/ / www.sculpteo.com/ blog/2016/12/14/ the-

history-of-3d-printing-3d-printing-technologies-fromthe-80s-to-today/.

[4] MOLIKOVA, E. (2006) Materials and Products Testing. [Online]. 20th January 2006 [seen 8th December 2013]. Available at: bttp:/ / ime.fme.vutbr.cz/files/Studijni\%20opory/zmv/Index. btml.

[5] KLOSKI, Liza Wallach a Nick KLOSKI. (2020). Začnáme s 3D tiskem. Brno: Computer Press, 2017. ISBN 978-80-251-4876-1.

[6] MARCINCIN, J. N., JANAK, M., MARCINCINOVA, L. N.(2012) Increasing of Product Quality Produced by Rapid Prototyping Technology. In: Manufacturing Technology, 2012, Vol. 12, No. 12, pp. 71-75. FME JEPU. Czech Republic.

[7] KRATOCHVÍLOVÁ, J. (2015) 3D tisk. Ústí nad Labem: Univerzita J.E. Purkyně v Ústí nad Labem, 2015. ISBN 978-80-7414-936-8.

[8] ČSN EN ISO 527-2. Plastics - Determination of tensile properties: Part 2: Part 2: Test conditions for moulding and extrusion plastics

[9] KELLNER, T., KYNCL, J., PITRMUC, Z., BERANEK, L., KANAK, M., KYNCL, M. (2020) Production Process Plan-ning in Additive Manufacturing and Conventional Machining Technology Manufacturing System. In: Manufacturing Technology, 2019, Vol. 19 (2), pp. 232-237. FME JEPU. Czech Republic.

[10] SEDLAK, J., CHLADIL, J., ČERNÝ, M., et al., Determination of mechanical properties of materials used for 3D printing. In: Manufacturing Technology, 2020, Vol. 20 (2), pp. 190-194. FME JEPU. Czech Republic.

[11] SEDLÁK, J., VANĚK, R., CHLADIL, J. (2018) Production of Assistance Brake for Mechanical Wheelchair. In: Manufacturing Techno$\log y$, 2018, Vol. 18, No. 3, pp. 487-492. FME JEPU. Czech Republic.

[12] SEDLÁK, J., KUDLÁČOVÁ, B., ZEMČíK, O., JAROŠ, A., SLANÝ, M. (2017) Production of Planetary Mechanism Model Prototype using Additive Method of Rapid Prototyping. In: Manufacturing Technology, 2017, Vol. 2017, No. 3, pp. 374-381. FME JEPU. Czech Republic.

[13] SEDLÁK, J., MALÁŠEK, J., ONDRA, M., POLZER, A. (2016) Development and Production of Prototype Model of Axial Fan. In: Manufacturing Technology, 2016, Vol. 2016, No. 2, pp. 436-444. FME JEPU. Czech Republic. 